\title{
The First Contraceptive
}

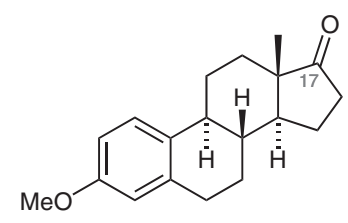

3-O-methylestrone

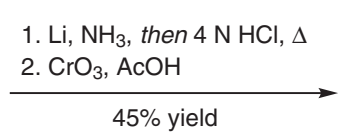

Birch reduction

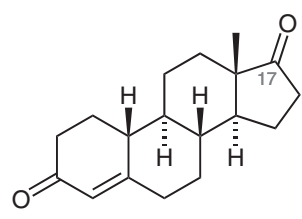

$\mathrm{CH}(\mathrm{OEt})_{3}$ pyridine $\bullet \mathrm{HCl}$ $\mathrm{EtOH}$<smiles>CCOC1=CC2=CCC3C(CCC4(C)C(=O)CCC34)C2CC1</smiles>

1. potassium tert-amylate, acetylene 2. $50 \% \mathrm{HCl}$ $64-78 \%$ yield
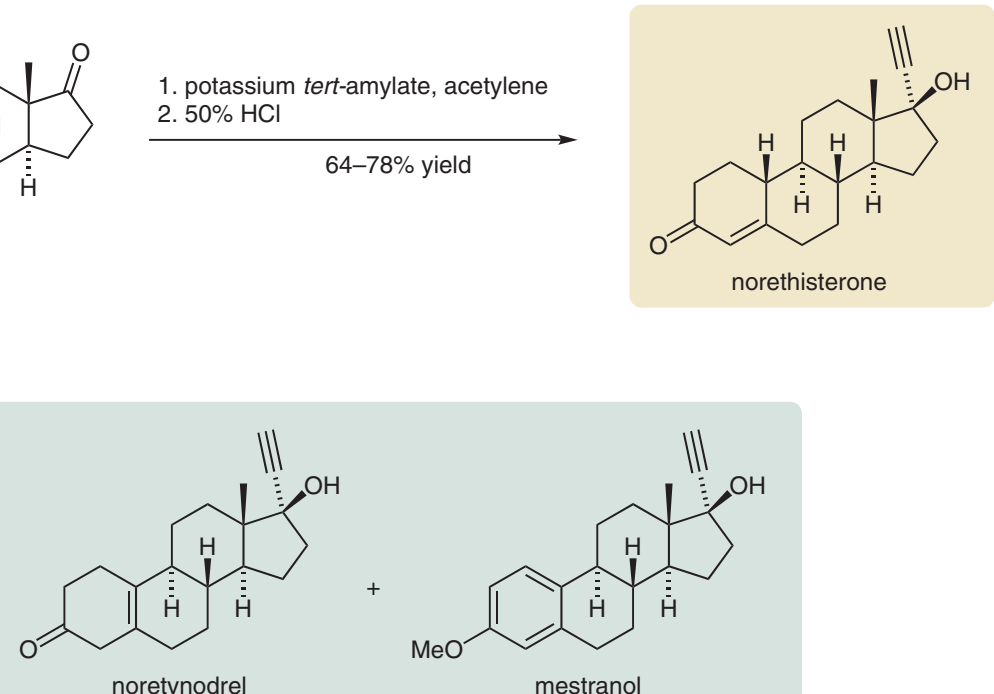

enovid

Significance: The combined oral contraceptive pill (COCP) gave women unprecedented control over their fertility and helped spark the sexual revolution. In 1951, Djerassi and co-workers at Syntex introduced norethisterone, the first orally available highly active progestin, thereby enabling the development of the COCP. In 1952, chemists at Searle synthesized noretynodrel, another orally available progestin and an isomer of norethisterone. The FDA approved the first COCP, Enovid, a mixture of noretynodrel and mestranol, in 1957 for menstrual disorders and, in 1960, as a contraceptive.
Comment: Norethisterone was synthesized by Birch reduction of 3-O-methylestrone, followed by hydrolysis of the methyl enol ether and reoxidation at $\mathrm{C} 17$. The enone was protected as the ethyl dieneol ether, followed by addition of acetylene and deprotection to yield norethisterone. The structure of noretynodrel was not covered by Syntex's patent and noretynodrel could thus be introduced by Searle.
Chemistry in

Medicine and

Biology

Key words

contraception

steroids

progestin

\section{Synfact}

